\title{
Limits and possibilities for the promotion of sustainable development: the case of Northwest Region Fluminense
}

\author{
D. C. Vivas Neto ${ }^{1} \&$ E. A. Nascimento ${ }^{2}$ \\ ${ }^{1}$ Pro-Rectory of Extension, Brazil \\ ${ }^{2}$ Federal Fluminense University, Brazil
}

\begin{abstract}
This paper aims to present partial results of the first stage of a participatory research conducted in the Northwest Region of the State of Rio de Janeiro, from July 2009 to June 2010. This region has the lowest HDI (Human Development Index) of the State of Rio de Janeiro, and the State Secretariat for Planning and Management projects for the next 25 years GDP to grow by only $4.11 \%$, in total for the Region Northwest Fluminense. This reality prompted the formation of a working group consisting of social actors such as community members, representatives from the local government and the Federal Fluminense University, aiming to build innovative forms of development for this region. In this sense, we conducted a participant survey whose main steps were: data collection of the socio-environmental region, and systematization of information collected through discussion groups and seminars. As a result we created the Board of Municipal Secretaries of the Environment - COSEMA. This Council empowers its members to promote dialogue of environmental public policies in the region, establishing itself as a strategy for encouragement in order to radiate toward the state and federal political levels.
\end{abstract}

Keywords: sustainable development, regional planning councils, governance.

\section{Introduction}

Brazil lives, from the early years of the XXI century, a resumption of economic growth, a process interrupted in the 80s. Major Projects and programs are being implemented in different regions that compose it. The state of Rio de Janeiro, a part of the Southeast, is one of the cities that have received large investments, 
particularly in sectors related to infrastructure of the oil and steel industries. This fact is extremely interesting and raises the need for monitoring by civil society, given that historically there was no equity in the spatial distribution of investments. This created an imbalance between regions, causing some of them to have their own development process compromised. The Northwest Fluminense is one of them, as will be shown in this article. At a time when growth is resumed, it is necessary with actions that work toward not only contributing to an equal distribution of resources, but also ensure the promotion of sustainable development.

The COSEMA is an entity committed to ensuring the achievement of these goals. Organized in 2009, it consists of the secretaries of the environment, with direct assistance of technicians from the Federal Fluminense University. Its creation has proved positive, it has contributed to the concept of sustainability being disseminated widely and incorporated in the administrations of the municipalities that compose it. It has also given visibility to the region in the state and national scene, which is important for fundraising. Moreover, it has contributed to the promotion of sustainability. These initial actions contribute to sustainability in political, economic and social environments. These have been the possibilities. However it has limits. As one of the technicians involved in advising, I see the lack of a deeper vision of sustainability and its meanings in the administrative setting. Still missing is the inclusion of other dimensions such as economic, demographic, cultural, institutional, technological and legal space.

\section{Northwest Fluminense: pictures of unsustainability}

The differentiated destination of economic resources between different regions of Brazil, due largely in recent years, is a result of the political alliances but primarily because of a development model - hub and exclusion. The first stage of this model starts from the 50s, when Sao Paulo and Rio de Janeiro were chosen to receive investments that would enable the structuring of industrial capital. The other states and regions have been relegated, causing a disruption to their economies and population depletion [1].

In the $70 \mathrm{~s}$, investments were directed to monopoly capital, to ensure conditions for its reproduction and expansion. In that context, it has become crucial "to create conditions for the development of reproductive dynamics (the capital) and infrastructure for its implementation" (Jacobi, 1989, 8). In this sense high investments were made mainly in industry power generation and at specific points, creating more disruption and deflation. At that time the RJ was not included, which caused a slowdown of their activities, with different implications in each of their regions $[2,3]$.

Northwest Fluminense was one of the most affected regions. The designation "North Fluminense" served to denote a portion of territory that covered the entire northern part of the State of Rio de Janeiro (Fig.1), without considering the current division into North and Northwest Fluminense. Until the 1970s, the territory was covered by Microregion of Campos, and the Micro-region of Itaperuna, Microregion of Miracema. The official name of North Fluminense 
occurred in 1975, along with the three micro-regions mentioned above, plus the city of Itaocara. In 1980, the name becomes North Fluminense Mesoregion. Only in 1987 the Greater Region Northwest Fluminense is separated from the North Mesoregion [4, 5].

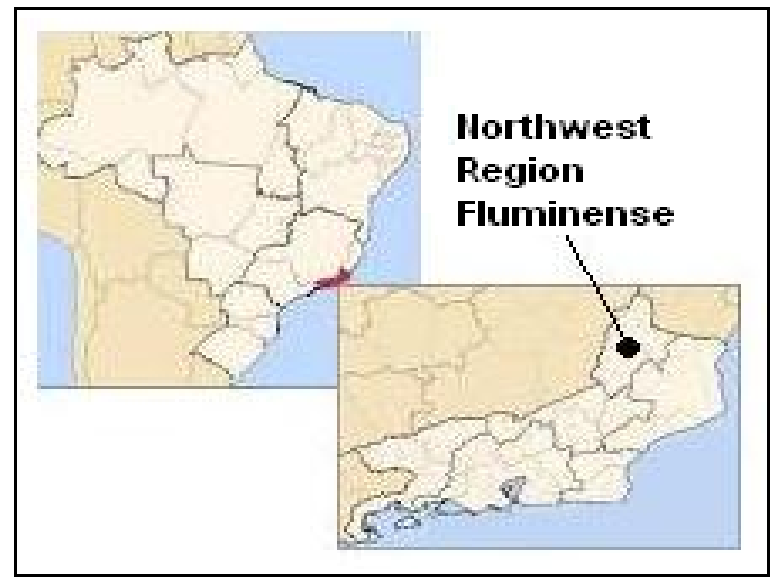

Figure 1: $\quad$ Northwest Region of Rio de Janeiro state.

With the economy based on the alcohol industry ("sucroalcooleira"), coffee and livestock production, the region known as the most innovative and dynamic state, suffered a huge decline in socioeconomic status from the $80 \mathrm{~s}$ of the 20 th Century in the context of national economic crisis and crisis of the state of Rio de Janeiro [4,5]. Today the region presents a framework for sustainability as show below:

The concept of "sustainability" expressed different dimensions and related concepts of organic and systemic ways. Hence the environmental sustainability, ecological sustainability, social sustainability, political sustainability, economic sustainability, demographic sustainability, cultural sustainability, institutional sustainability, territorial sustainability, technological sustainability and legal sustainability. For a brief analysis of the unsustainability of the Northwest Region we will take as a reference the environmental, social and economic sustainability [6,7].

Economic unsustainability - The Northwest Fluminense is showing inefficiency in the management of financial and natural resources, characterized by irregular flow of public and private investments, according to a macro assessment.

The PIB of State in 2007 was R\$ 324,370,491,236.30, which the Metropolitan Region of Rio de Janeiro accounted for $73.61 \%$, followed by North Fluminense with $10.79 \%$, the South with $7.58 \%$, the Baixada with $5.18 \%$, the Centre with $1.77 \%$ and finally the Northwest Region with $1.07 \%$, this was the area that contributed the least to the generation of wealth in the State of Rio de Janeiro [4]. 
Environmental unsustainability - The Region Northwest Fluminense in the face of anthropogenic interference, throughout its history of occupation, its ecosystems had changed significantly, reducing or even preventing the natural self-purification that still exists.

Its cover was dramatically changed due to the occurrence of fire and clearing for agricultural exploitation. Biodiversity loss is also closely linked to land conflicts by urban sprawl in areas of risk or protection.

The present forest fragments are small and dispersed, causing dryness of the soil. This is a significant environmental harm, given that it increases the risk of erosion.

The Atlantic Forest, before existing, mostly gave way to pastures, which occupy most of the Northwest region and are distributed in all types of relief. These areas are up to four times the amount of forest cover remaining. However, although the grasslands occupy large tracts of land, they do not guarantee a large livestock production, since these have low productivity because of soil degradation $[4,5]$.

The rainfall in the region has decreased considerably over the last 40 years. The distribution of average annual rainfall records low levels in the region ranging between $750 \mathrm{~mm}$ and 1,250 $\mathrm{mm}$ per year [5].

Regarding water supply, the Northwest region has experienced serious supply constraints, both for human and animal consumption, due to the scarcity of recent years. Rampant deforestation of the few remaining forests, use and inadequate management of soil erosion has led to making the soil less permeable. Another contributing factor to this scenario is low and poorly distributed rainfall, which is concentrated in the summer months, causing rivers, streams and shallow wells dry up the region for most of the year. Thus there is a loss for the full recharge of water systems, leading to the disappearance of temporary rivers, siltation of rivers and the disappearance of springs, which compromises the integrity of ecosystems [5].

Social unsustainability - The Northwest region presents intergenerational cycles of poverty and chronic poverty, lower average education level, low levels of income for most of the economically active population, migration, urban violence and crime. This region has the lowest HDI (Human Development Index) of the State of Rio de Janeiro and the State Secretariat for Planning and Management projects for the next 25 years the GDP to grow only by $4.11 \%$, in total for Region Northwest Fluminense. The chart below shows a scenario for 2035, comparing the evolution of PIB between the North and Northwest Fluminense $[4,5]$.

The large informal labor market and areas of poverty, with a visible lack of infrastructure, show that the Northwest presents itself impoverished and weakened in various social areas. The region faces a shortage of qualified manpower, wherefore local initiatives need measures of productivity and commercialization.

The existing scenario in the region is that environmental, economic and social rights are incompatible with sustainable development proposals drawn from the $80 \mathrm{~s}$. The challenge posed is the pursuit of development. In the next section will 


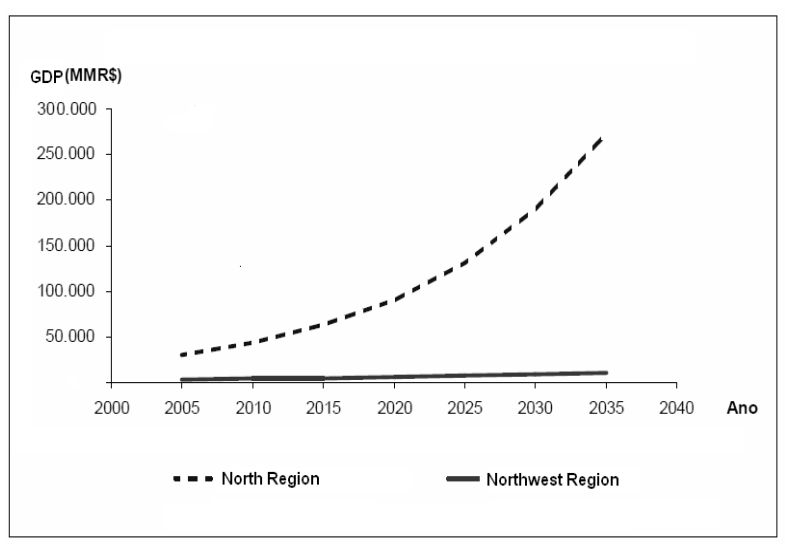

Figure 2: $\quad$ North and Northwest region Fluminense, GDP, 2005-2035.

be shown how the actions of the Council of Secretaries of the Environment has contributed to overcoming this challenge.

\subsection{The councils as alternative sustainable development}

The presence of the Fluminense Federal University in the region, through extension activities, allowed an assessment of the issue and the organization of a working group.

During the performance of the National Environmental Health Conference, in São José de Ubá, Rio de Janeiro, in 2009, was presented to the plenary, to vote on the proposal for a council meeting secretaries of the area's environment. In the recent history of Brazil can be identified at least three types of councils:

a) government - these were created by the executive government in the context of populist governments, taking a mediating role between the government and society, represented by popular movements and organizations;

b) popular - emerged in the popular movements to facilitate negotiations with the government, notably in health, education, services and urban facilities, and;

c) institutionalized - these were created by laws from the legislative branch, with opportunities to participate in the management of public affairs. They are management councils, created from the 90s [8].

This method was considered to be interesting for the purpose of moving toward sustainability.

The COSEMA has the following characteristics:

- It is composed of secretaries of the environment.

- It has regional coverage - territorial scale intermediate between the state and municipality.

- It has as its goal the promotion of sustainable development in its many dimensions - public policies of the long-term.

- It has direct technical assistance to public universities and research centers. 
- The work methodology consists of participatory research, whose development was based on procedures built by Bellagio [9]. According to the author is required:

- To have a clear vision of sustainable development and goals that define it;

- To revise the current system as a whole and in parts, considering the well-being of social, ecological and economical subsystems, its states, to change the direction and rate of change in relation to these states and their interrelationships;

- To consider the positive and negative consequences of human activities in ways that reflect the costs and benefits to humans and ecological systems, in monetary and non-monetary ways;

- To consider the issues of equality and disparity between the current population and between present and future generations, evaluating the use of resource consumption and poverty, human rights and access to basic services;

- To consider the ecological conditions of which life depends;

- To consider economic and other activities outside the market, contributing to human welfare and social development;

- To adopt a plan of long horizon - long enough to cover the time scales of human and natural ecosystems, thus responding to the needs of future generations, but also those who need short-term planning;

- To define the scope of work, broad enough to include the impacts locally and regionally (globally) on the population and ecosystems, based on historical and current conditions to anticipate future conditions - where to go, where one can go, and

- To use an organizational structure that connects the vision and goals to indicators and assessment criteria, using a limited number of points for analysis, a limited number or combination of indicators to get a clearer signal of the process, standardize measures when possible, to allow comparisons, comparing indicator values to targets, reference values or limits.

- The methods and data must be accessible to everyone, all judgments, assumed values and uncertainties in data and interpretations should be provided.

- To be designed to meet the needs of the community and its users, using indicators and other tools that can stimulate and bring the attention of governments, seeking simplicity in structure and use accessible language.

- To obtain effective community representation, professional people, social groups and technicians, to ensure diversity and recognition of values used. 
possibility of changing complexity of the systems, structures set goals and indicators as new knowledge and ideas are coming; promote the awareness of society so that it can meet those who make the decision.

- Indicate responsibilities and obtain priority in the management process and decision; provide institutional capacity for collection, maintenance and documentation of data, and, ensure and provide capacity to local assessment.

\subsubsection{The actions of the board}

So far several actions can be identified at the municipal, regional, state and federal levels, as shown below:

Expansion and dissemination of the concept of sustainability - Although board members had as its goal the construction of sustainability, they lacked an understanding of the meaning of it. With the advice of the University were conducted workshops in which they had the opportunity to discuss the concept in general and the operation in the region.

Promotion of political articulation - The COSEMA created an agenda of meetings with the aim of presenting the reality experienced by the secretaries in their respective municipal units. During these meetings the secretary that had not shared their difficulties, began a process of conversation. Thus was organized by COSEMA a meeting in the Miracema city, with the presence of the Secretary of State for Environment (SEA), Chairman of the State Authority for Environmental (INEA), the region's Mayors, Secretaries of the environment, civil defense and education, and civil servants of secretariats, and Fluminense Federal University. Through the elaboration of strategies, discussed in meetings between the secretaries, are certain plans of action made, with the objective of coordinating the various municipalities within the region and state and federal government.

Systemic and holistic approach to the problems - the environmental, social and economic commitment, development that hitherto was not discussed or discussed piecemeal, for each municipality, now begin to have a systemic and holistic approach at regional level. The most significant example is facing the problem of flooding in the region. Before the creation of COSEMA, the problems were treated in a timely fashion, being confined to assistance in engineering, without any reference to environmental issues. Today it's part of the agenda of the meetings that address this problem, deforestation and the need for reforestation, the illegal occupation of marginal strips and the need for a housing policy in the region, the release of waste into rivers and the need for a sanitation policy and change of the local culture through Ecocidadania program. The incorporation of these issues by COSEMA has occurred through a new performance of secretaries with regard to the implementation of environmental education. This was confined to the bead of the secretary of education, addressing in a timely manner, the physical, chemical and biological aspects. The reflections of the members of COSEMA, especially those relating to sustainability and its dimensions, have contributed to some actions being implemented in municipal management. One of them within the basic education 
was a bailout of the municipal gardens, which were solely linked to the production of exotic fruit tree seedlings, now presenting themselves as pedagogical space to develop projects and programs offered by Ecocidadania to the local community. Besides the production of seedlings of exotic trees, some day nurseries produce tree seedlings of Atlantic native, for the reforestation of degraded areas and to farmers for planting in the areas of permanent preservation - APP on their properties. The next step is to establish the region as a major producer of tree seedlings in the Atlantic Forest, since the state lacks sufficient seedlings to meet demand for planting.

Regional articulation - Despite having been important in the past and may take a strategic position in the economic outlook, the Northwest Fluminense had little visibility in the state and on federal level. Visibility and articulation of COSEMA in federal and state administrations allowed the purchase of an accent on CONAMA, the only region of the state of the CONAMA environment at the federal level. The presence of representatives from Northwest Fluminense in this important region gives advice on environmental scenarios. And by presenting their needs, they can obtain the resources or make laws that help to address issues specific to the region as well as other regions who suffer from the same issue.

Strengthening of regional social and environmental identity - Although close, the municipal units are unaware of the reality of their neighboring counties, in social, political, environmental and institutional aspects. During the workshops held in the Clerks COSEMA environmental rescue stories of the occupation, the impact of economic activities on the environment, especially in their agropastoral districts also had the characteristic and difficulty of their respective municipalities, which were discussed by all contributing to the formulation of proposals to confront these issues at the regional level.

Addressing issues from the perspective of sustainability - Data and information presented at meetings by members of COSEMA are disclosed in their respective halls. Although there is still public policies for sustainable development in the region, this procedure is an established concern on the municipal and state levels. An example is the routing that is being given to disposal of solid waste in the region, the waste from each municipality was discarded improperly, so participants of COSEMA act as organizers and facilitators in the process of building the Northwest Landfill II.

Fundraising - To lessen the difficulty of obtaining financial resources and materials, the members of COSEMA identifying the lack of material from the Department and which threatened the progress of environmental management activities in the municipalities, has drafted a proposal that included the acquisition needs of equipment by the departments in the region and collectively presented this proposal to state power. Another strategy observed in the activities of COSEMA, was to strengthen the discussion on the GST-Eco Programme of the state government to transfer resources to municipalities from the achievement of goals related to improving the environmental capital of the municipalities. Socialization strategies for access to the resource-ecological ICMS enabled the 
increase in tax collection by municipalities and to later transfer these resources to the departments of environment.

The monitoring of activities with low environmental impact, is undergoing a process of decentralization, leaving the municipalities to perform them. On one side this brings the resources to fund municipal environment, but then requires the existence of a qualified and diverse staff. However, the individual local municipalities did not have human resources to meet this demand. The COSEMA suggested creating a database of experts consisting of professionals from municipalities of the region, the idea is that this bank account not only supervision, but also other needs of the region.

\section{Conclusion}

As shown at the beginning of this article, COSEMA has among its goals the overcoming of unsustainability and the promotion of sustainable development for the region. Of course this requires a long period of time and the presence of several actors of all segments of society. Community participation is important, especially for the historically excluded. We must create effective channels of social participation of the grassroots, encouraging the presentation of demands, dreams and contributions coming from the living land.

It also requires effective environmental education programs, formal and informal, and at all levels of education. At the top level, which prepares future managers and technicians, the inclusion of environmental education becomes more necessary.

And finally, we consider the important role of state and federal governments in the determination of sustainable strategies in formulating their plans, in the short, medium and long term.

Therefore, the actions of COSEMA must be accompanied by strategies that enable the participation of society, contributing to the implementation of environmental education programs and public policies that contribute to sustainable development.

Despite the non-fulfillment of these requirements, the action of COSEMA has been important in combating the environmental unsustainability, above all in relation to the recovery of degraded areas by planting and production of forest seedlings. These actions will help to reverse the sedimentation basin that we observe in the fabric of the region, facilitating the replenishment of aquifers and therefore alter the microclimate of the region, competing with more stable levels of humidity and temperature. The COSEMA has spurred the creation of conservation units in the municipalities of San José de Ubá, Santo Antônio de Pádua and Miracema. These units have already been created for prediction of new ones. The creation of a network of protected natural area, points to a sustainable management of biodiversity, establishing the connectivity of forest fragments and preventing the extinction of endemic species in the region.

An important fact is that the departments of environment in the region, while critical sectors of the municipal administration were neglected in relation to financial resources and personnel, did not have enough space and did not have 
financial resources and personnel, did not have enough space and did not have estimates of appeal in the municipal budget, lacked a local action plan. COSEMA with the actions of the municipal environment has been strengthened politically and technically, enlarging the channels of conversation and possible involvement in the sustainable management of municipal and regional level. As demonstrated, the possibilities are endless and the limits for establishment of sustainable development in the region tend to be overcome by strengthening COSEMA, that can be achieved through the contribution of universities under extension, teaching and research.

\section{References}

[1] Abreu, M.A. A Evolução Urbana no Rio de Janeiro. Zahar: Rio de Janeiro, 1988. - book

[2] Pochmann, M \& Amorim, R. A exclusão social no Brasil. Cortez: São Paulo, 2003. - book

[3] Castells, M. A. Questão urbana. Paz e Terra: Rio de Janeiro, 1983. - book

[4] Secretaria Estadual de Planejamento e Gestão Rio de Janeiro. Plano de Desenvolvimento Sustentável do Norte e Noroeste do Estado do Rio de Janeiro: (Cenários e Estratégias), 2010. - Report

[5] Secretaria Estadual de Planejamento e Gestão Rio de Janeiro. Plano de Desenvolvimento Sustentável do Norte e Noroeste do Estado do Rio de Janeiro: (Análise SituacionaI), 2010. - Report

[6] Bidone, E.D. \& Morales, P.R.D. Introdução a noção de desenvolvimento sustentável In:_. Desenvolvimento sustentável e engenharia. Rio de Janeiro: Fundação Ricardo Franco, 2004. p.17-34. - chapter in a book

[7] Sachs, I. Caminhos para o desenvolvimento sustentável. Rio de Janeiro: Garamond, 2009. 96p. - book

[8] Gohn, M.G. Conselhos populares e participação popular. In: Conselhos gestores e participação sociopolítica. São Paulo: Cortez, 2001. p.65-82. - chapter in a book

[9] Philippi Jr., A. Pelicione, M.C.F., Saúde ambiental e desenvolvimento. In: Educação ambiental. São Paulo, 2005. p.59-84. - chapter in a book 